\title{
Oral Bioavailability Enhancement of Raloxifene with Nanostructured Lipid Carriers
}

\author{
Aditya Murthy ${ }^{1,2}$, Punna Rao Ravi ${ }^{2, *} \mathbb{C}$, Himanshu Kathuria ${ }^{2,3}\left(\mathbb{C}\right.$ and Shrinivas Malekar ${ }^{2}$ \\ 1 Differentiated Formulations, Strides Pharma Science Ltd., R \& D Centre, J.P. Nagar 2nd Phase, \\ Bangalore 560083, Karnataka, India; adityamurthy1212@gmail.com \\ 2 Department of Pharmacy, BITS-Pilani Hyderabad Campus, Hyderabad 500078, Telangana, India; \\ himanshukathuria01@u.nus.edu (H.K.); malekarshrinivas@gmail.com (S.M.) \\ 3 Department of Pharmacy, National University of Singapore, 18 Science Drive 4, Singapore 117543, Singapore \\ * Correspondence: rpunnarao@hyderabad.bits-pilani.ac.in or rpunnarao@gmail.com; Tel.: +91-40-66303539
}

Received: 17 April 2020; Accepted: 15 May 2020; Published: 31 May 2020

\begin{abstract}
Raloxifene hydrochloride (RLX) shows poor bioavailability $(<2 \%)$, high inter-patient variability and extensive gut metabolism $(>90 \%)$. The objective of this study was to develop nanostructured lipid carriers (NLCs) for RLX to enhance its bioavailability. The NLC formulations were produced with glyceryl tribehenate and oleic acid. The particle characteristics, entrapment efficiency (EE), differential scanning calorimetry (DSC), in vitro drug release, oral bioavailability (in rats) and stability studies were performed. The optimized nanoparticles were $120 \pm 3 \mathrm{~nm}$ in size with positive zeta potential $(14.4 \pm 0.5 \mathrm{mV})$; \% EE was over $90 \%$ with the drug loading of $5 \%$. The RLX exists in an amorphous form in the lipid matrix. The optimized RLX-NLC formulation showed sustained release in vitro. The RLX-NLC significantly $(p<0.05)$ enhanced oral bioavailability 3.19-fold as compared to RLX-free suspension in female Wistar rats. The RLX-NLC can potentially enhance the oral bioavailability of RLX. It can also improve the storage stability.
\end{abstract}

Keywords: solid lipid nanoparticle; nanostructured lipid carriers; bioavailability; glyceryl behenate; raloxifene; osteoporosis

\section{Introduction}

Osteoporosis is a disease condition with a greater risk of fracture as a cause of decrease in bone mineral density and bone quality [1]. There are many reported causes for osteoporosis, but menopause is the most common and potential cause. Post-menopause, levels of the estrogen fall which leads to disturbed density of bone minerals with susceptibility to bone fractures [2]. It affects women worldwide including in Europe, USA and Japan [3,4]. Raloxifene hydrochloride (RLX) is a popular selective estrogen receptor modulator [5], which is used to prevent and treat postmenopausal osteoporosis. It has proven effective to preserve bone density, preventing the incidence of vertebral fractures in postmenopausal women [5,6]. It is also used for the treatment of breast cancer [5,7]. According to the Biopharmaceutics classification system and the Biopharmaceutics drug disposition classification system, RLX is Class II drug [8]. RLX is highly permeable and absorbed $60 \%$ by the oral route; however, its bioavailability is only $2 \%$ in humans as a cause of extensive pre-systemic intestinal glucuronidation and permeability glycoprotein (Pgp) efflux $[9,10]$. The bioavailability of RLX in animals varies with species from $0-39 \%$ [11].

The oral route is the most preferred route for the administration of drugs as it offers the greatest patient compliance. It accounts for more than a 50\% share of the global drug delivery market [12]. The various approaches for the oral bioavailability enhancement of RLX, such as dry suspensions of cyclodextrin inclusion complexes [13], mesoporous carbon nanospheres [14], proliposome powders [15], 
solid dispersions [16,17] and self-microemulsifying drug delivery system solids [18] have been explored previously. Lipid nanocarriers can be suitable nanocarriers for RLX owing to their capability to mainly deliver poorly soluble and lipophilic drugs [19]. Lipid nanocarriers have also been shown to decrease inter-individual variability [20]. The orally administered lipid nanoparticles enter into systemic circulation by different uptake mechanisms such as receptor-mediated endocytosis, non-specific transcellular transport, paracellular transport and M-cell-mediated transport [21]. The enhanced oral bioavailability of drugs loaded in solid lipid nanoparticles (SLNs) is due to their small particle size, increased surface area and surface properties (like charge) that improve their bioadhesion to the gut wall, leading to prolonged residence time in the gastrointestinal tract (GIT). Moreover, the production of the mono and diacylglycerols during the digestion of triglycerides by lipases in the GIT induces the secretion of bile salts that together with mon and diacylglycerols form micelles. These micelles further help to enhance the oral absorption of drugs. Moreover, SLNs can also facilitate lymphatic transport by initiating the formation of lipoprotein and intestinal lipid flux giving the bulk bioavailability of drugs [22]. The composition of SLNs and its excipients such as the amount of surfactant can significantly change the particle size, which also affects the lymphatic transport. The direct uptake of lipid nanocarriers through M-cells and lymphatic transport also plays the major role in the enhancement of their bioavailability [23].

In recent years, lipid nanocarriers have been shown to enhance the oral bioavailability of RLX [11,17,24-26]. Nanostructured lipid carriers (NLCs) are the modification of solid lipid nanoparticles (SLNs) in which part of the solid is replaced by another solid lipid or an oil [27]. The limitations of SLN-like drug expulsion during storage and low entrapment efficiency were studied by the researcher leading to the development of a second generation of SLNs as NLCs $[27,28]$. It was shown to have better physical stability than SLNs by reducing the expulsion of the drug during storage. Replacing the part of the solid lipid by an oil causes an imperfection in the lattice structure of solid lipids. The increased imperfections in the solid lipid lessen the chance of drug expulsion during storage while retaining the loading capacity; hence, this improves formulation stability as compared to SLNs [27,29]. Recently, Puro et al. reported the transdermal delivery of raloxifene using NLCs, which were later loaded into gel for topical application [30]. Shah NV et al. described RLX-loaded NLCs based on glyceryl monosterate, formulated using the solvent diffusion method, which involves multiple steps in addition to the use of toxic organic solvents [31]. In contrast, the hot homogenization method involves a lesser number of steps and minimal factors to optimize the formulation, which can be easily controlled. Moreover, the hot homogenization can eliminate the use of toxic organic solvents; hence, avoiding potential safety hazards.

In this study, we formulated the RLX-loaded NLCs to enhance its oral bioavailability and improved stability. The RLX-NLCs were prepared with glyceryl behenate (solid lipid) and oleic acid (liquid lipid) similarly to a previously reported method from our group for the preparation of SLNs [11,32]. The optimization was done based on factors such as surfactant concentration, sonication time and lipid amount. The particle characteristics (size, zeta potential and polydispersity index (PDI)) and entrapment efficiency were taken as the responses to optimize the formulation. The optimized formulation was carried forwards for its in vitro release, then the oral bioavailability studies in female Wistar rats to prove its potential in bioavailability enhancement and finally the formulation stability.

\section{Materials and Methods}

\subsection{Materials}

The raloxifene hydrochloride was obtained as a gift sample from Apotex Research Pvt. Ltd., Bangalore, India. The high purity glyceryl tribehenate $\left(\mathrm{C}_{69} \mathrm{H}_{134} \mathrm{O}_{6}\right.$, molecular weight $\left.1059.8 \mathrm{~g} / \mathrm{mol}\right)$ was purchased from M/s Himedia Pvt. Ltd. (Hyderabad, India). The Kolliphor P407 (poloxamer 407) (P407) and mannitol were procured form Signet Chemicals, Mumbai, India. The oleic acid was procured from SD fine chemicals Ltd., Mumbai. All the other chemicals used were of analytical grade and the 
solvents were of high performance liquid chromatography (HPLC) grade. Freshly collected Milli-Q water (Millipore, Billerica, MA, USA) was used in the formulation preparation and the preparation of the aqueous mobile phase of the HPLC analysis.

\subsection{Preparation of NLC}

All the formulations were prepared by a hot homogenization process followed by ultra-sonication. Firstly, glyceryl behenate and oleic acid were melted in a $100 \mathrm{~mL}$ glass beaker maintained at a temperature of $80{ }^{\circ} \mathrm{C} \pm 4{ }^{\circ} \mathrm{C}$ using a silicone bath with a magnetic stirrer. The drug was added with the melted lipid-oil mixture and stirred for uniform mixing. The aqueous phase consisted of P407 dissolved in the cold water using a magnetic stirrer (Model: 1MLH, REMI Labworld, Mumbai, India) at $1000 \mathrm{rpm}$. The aqueous phase was maintained at the same temperature as that of the molten lipid phase to prevent recrystallization during stirring. The hot aqueous phase was added drop wise into the oil phase with continuous stirring at $1000 \mathrm{rpm}$ for $5 \mathrm{~min}$ to form pre-emulsion. It was then homogenized using a high shear homogenizer (Polytron PT 3100D, Kinematica, Lucerne, Switzerland) at 10,000 rpm for $5 \mathrm{~min}$ and subjected to sonication using a probe Sonicator (Vibra cell, Sonics, Newtown, CT, USA) on pulse mode (20 s sonication $10 \mathrm{~s}$ off cycle; attached with $\frac{3}{4}$ " solid tapered tip that could vibrate up to $120 \mu \mathrm{m}$ amplitude at 100\%) for varied time intervals (Table 1) to form nanoemulsions. Subsequently, the nanoemulsions was rapidly cooled down in an ice bath to form NLCs and finally diluted up to $50 \mathrm{~mL}$ by the addition of $20 \mathrm{~mL}$ cold water $\left(1-2{ }^{\circ} \mathrm{C}\right)$ and incubating that in an ice bath for $15 \mathrm{~min}$. The final NLC dispersions were stored at $4{ }^{\circ} \mathrm{C}$ and at room temperature for further analyses.

\subsection{Formulation Optimization}

Firstly, the method of preparation was optimized followed by the formulation optimization which was done by keeping the phase ratio constant; the effects of magnetic stirring, homogenization and sonication were observed individually and in combination. Secondly, for optimizing the NLC formulation, various parameters were studied sequentially. It was done by varying factors in the following sequence: the amount of oleic acid, the surfactant concentration and then the sonication time. The P407 concentration referred to the \% P407 used to make the formulation, while the final P407 concentration after dilution with water was lesser than that shown in Table 1 . Herein, the \% P407 in the final formulation was $1 \%, 2 \%$ and $3 \%$. The particle characteristics like the particle size (Z-average, $\mathrm{d} 50, \mathrm{~d} 90, \mathrm{~d} 95)$, PDI, zeta potential and the formulation characteristics like the $\% \mathrm{EE}$ and the percentage of cumulative release (\% CR) were measured as responses (See Table 1).

Table 1. Composition and the variables (HT-homogenization time, ST-sonication time) of various nanostructured lipid carrier (NLC) formulations for optimization. The \% P407 refers to the concentration used to prepare the NLCs while the final \% P407 will be lesser after the dilution to $50 \mathrm{~mL}$.

\begin{tabular}{cccccccc}
\hline Code & $\begin{array}{c}\text { Drug } \\
(\mathbf{m g})\end{array}$ & $\begin{array}{c}\text { Glyceryl } \\
\text { Behenate } \\
\mathbf{( g )}\end{array}$ & $\begin{array}{c}\text { Oleic } \\
\text { Acid } \\
\mathbf{( g )}\end{array}$ & $\begin{array}{c}\mathbf{P} \text { 407 } \\
(\mathbf{\%} \boldsymbol{w} / \boldsymbol{v},[\mathbf{m L}])\end{array}$ & $\begin{array}{c}\text { Water q.s. } \\
(\mathbf{m L})\end{array}$ & $\begin{array}{c}\text { HT } \\
(\mathbf{m i n})\end{array}$ & $\begin{array}{c}\text { ST } \\
(\mathbf{m i n})\end{array}$ \\
\hline NLC 1 & NA & 0.7 & 0.3 & $5.0[20]$ & 50 & 3 & 10 \\
NLC 2 & 50 & 0.7 & 0.3 & $5.0[20]$ & 50 & NA & 10 \\
NLC 3 & 50 & 0.7 & 0.3 & $5.0[20]$ & 50 & 3 & 10 \\
NLC 4 & 50 & 0.7 & 0.3 & $5.0[20]$ & 50 & 3 & 20 \\
NLC 5 & 50 & 0.7 & 0.3 & $2.5[20]$ & 50 & 3 & 10 \\
NLC 6 & 50 & 0.7 & 0.3 & $7.5[20]$ & 50 & 3 & 10 \\
NLC 7 & 50 & 0.77 & 0.23 & $5.0[20]$ & 50 & 3 & 10 \\
NLC 8 & 50 & 0.83 & 0.17 & $5.0[20]$ & 50 & 3 & 10 \\
NLC 9 & 50 & 0.89 & 0.09 & $5.0[20]$ & 50 & 3 & 10 \\
\hline
\end{tabular}




\subsection{Assay Method}

A total of $200 \mu \mathrm{L}$ of the formulation was added to $800 \mu \mathrm{L}$ of chloroform to completely dissolve the lipid part. Then, the above mixture was evaporated to remove all the volatile content like water and chloroform by placing it in a hot air oven for $30 \mathrm{~min}$ at $60^{\circ} \mathrm{C}$. Subsequently, $10 \mathrm{~mL}$ of methanol was added into the dried mixture for the reconstitution of RLX. The glyceryl behenate was insoluble in methanol while the drug was freely soluble. The methanolic solution of the drug was analysed in HPLC (Model LC-20AD, Prominence Liquid Chromatograph, Shimadzu Corporation, Kyoto, Japan) using a validated method after suitable dilution [33].

\subsection{Entrapment Efficiency}

The free drug content was measured by the dialysis bag method. The dialysis method was chosen after unsuccessful attempts to separate the free drug and the nanoparticles using a centrifugation method. An amount of $5 \mathrm{~mL}$ formulation was taken into the dialysis bag (Spectra por 2, Fisher scientific, Waltham, MA, USA) with molecular weight cut off of 12-14 kDa, and kept in $140 \mathrm{~mL}$ dialysis media (pH 7.4 phosphate buffer and polyethylene glycol 400 (PEG-400) in the ratio of 4:1) under $150 \mathrm{rpm}$ in a modified type I dissolution apparatus for a maximum of $3 \mathrm{~h}$. This method was validated by spiking the free drug solution into a placebo NLC formulation and ensuring over $95 \%$ drug recovery in a $2 \mathrm{~h}$ period. The media volume was $140 \mathrm{~mL}$, ensuring that the sink condition was maintained, whereas the drug concentration in the release media was not more than $35 \mu \mathrm{g} / \mathrm{mL}$, which was nearly 10 times higher than that of the drug solubility i.e., $300 \mu \mathrm{g} / \mathrm{mL}$. The samples were collected at 1,2 and $3 \mathrm{~h}$ to ensure the reliability of the method for each measurement, and were later analysed in HPLC using a validated method.

The percentage entrapment efficiency (\% EE) was calculated using the formula mentioned in Equation (1):

$$
\text { Percentage EE }(\% \text { EE })=\frac{X_{\text {total }}-X_{\text {free }}}{X_{\text {total }}} \times 100
$$

where $X_{\text {total }}$ : total amount of RLX loading obtained using the formulation assay; $X_{\text {free }}$ : free RLX in the media obtained using the dialysis method.

\subsection{Particle Size and Zeta Potential}

The particle size was measured using dynamic light scattering and the zeta potential was measured using electrophoretic light scattering. The particle size was calculated as the particle size diameter (Z-average, d50, d90, d95) of the main population and the PDI was calculated as a measure of the width of the particle size distribution using a Malvern Zetasizer NANO ZS (ver. 6.01 MALVER Instrument Ltd., Worcestershire, UK). The formulation samples were analysed for the particle size and zeta potential in the automatic run mode, which allowed for repeated measurements with accuracy. The measurements were run at $25^{\circ} \mathrm{C}$ with 2 min of equilibration time. The zeta potential of the formulations was measured using the same equipment with a folded capillary zeta cell. All the measurements were done in triplicate.

\subsection{Differential Scanning Calorimetry}

The differential scanning calorimetry (DSC) was done for the RLX, glyceryl behenate, P407 and the melt dispersion of glyceryl behenate with RLX and oleic acid. The melting dispersion was prepared by dissolving the RLX in the melting of glyceryl behenate with oleic acid (10 and 30\% w/w). The thermal analysis was performed using a DSC 60 (SHIMADZU Corporation, Kyoto, Japan). Firstly, the heating chamber was equilibrated at $35^{\circ} \mathrm{C}$ and then $2 \mathrm{mg}$ samples were accurately weighted and sealed in an aluminium pan. The sealed aluminium (with the sample) pan was placed on sample plate and an empty sealed aluminium pan on the other plate as a reference. The nitrogen gas flow of $30 \mathrm{~mL} / \mathrm{min}$ 
was used to purge the system; the heating temperature was in the range $35-300{ }^{\circ} \mathrm{C}$ at a heating rate of $10{ }^{\circ} \mathrm{C} / \mathrm{min}$.

\subsection{In Vitro Drug Release}

The release study was done using the dialysis bag method. Here, $2 \mathrm{~mL}$ formulation was taken into the dialysis bag. The dialysis membrane was put into the $140 \mathrm{~mL}$ of media $(0.1 \mathrm{~N} \mathrm{HCl}(2 \mathrm{~h})$ and pH 6.8 phosphate buffer for up to $12 \mathrm{~h}$ ) in a $250 \mathrm{~mL}$ beaker at $37^{\circ} \mathrm{C} \pm 0.5^{\circ} \mathrm{C}$ with continuous stirring at $100 \mathrm{rpm}$. An amount of $0.1 \% \mathrm{v} / \mathrm{v}$ Tween was also added to the media to ensure the sink condition. Then, $140 \mathrm{~mL}$ media volume was taken to ensure that the sink condition was maintained, and even if the whole drug would dissolve in the media, then it would produce a concentration of no more than $14 \mu \mathrm{g} / \mathrm{mL}$, which was more than 20 times that of our drug solubility. At various time points $(0.083$, $0.25,0.5,1,1.5,2,3,4,6,8,12 \mathrm{~h}), 2 \mathrm{~mL}$ samples were collected and an equal volume of the media was replaced. All the samples were analysed in HPLC using a validated method.

\subsection{Stability Studies}

The accelerated stability studies were carried out for the optimized RLX-NLC as per the guidelines of the International Conference on Harmonisation Q1A (R2) (2003). The formulation was stored in three $50 \mathrm{~mL}$ transparent tarson tubes in a stability chamber maintained at $25{ }^{\circ} \mathrm{C} \pm 2{ }^{\circ} \mathrm{C} / 60 \% \pm 5 \%$ relative humidity $(\mathrm{RH})$. It was subjected to a stability test over a 6-month period for particle size, PDI, zeta potential and \% EE with sampling times of 1 month, 3 months and 6 months. Likewise, 3 tubes were kept in cold conditions at $4{ }^{\circ} \mathrm{C}$ and the stability was measured for 6 months. The reduction in the entrapment efficiency over time could affect the bioavailability enhancement, which may compromise the therapeutic effect of the formulation. The changes in the entrapment efficiency over 6 months was measured to observe the stability of the formulation, which can ensure that the effectiveness of the NLC formulation remains the same over time.

\subsection{In Vivo Pharmacokinetics}

The experiment was carried out in female Wistar rats which were fasted overnight for $12 \mathrm{~h}$ with access to water only. They were acclimatized to the environment one day before the experiment. The rats were divided into two groups of 3 each for the control (RLX suspension) and the test (RLX-NLC, NLC 3) groups. The two groups of rats were housed separately in propylene cages $(38 \mathrm{~cm} \times 23 \mathrm{~cm}$ $\times 10 \mathrm{~cm}$ under laboratory conditions of a controlled environment at a temperature $25^{\circ} \mathrm{C} \pm 2{ }^{\circ} \mathrm{C}$ and $60 \% \pm 5 \%$ RH. All the animals were dosed at 00:30 p.m. and the RLX was suspended in water using methylcellulose to give a concentration of $1 \mathrm{mg} / \mathrm{mL}$. The volume of administration was $15 \mathrm{~mL} / \mathrm{kg}$ and the doses were $15 \mathrm{mg} / \mathrm{kg}$ in all the control group animals. The formulations were administered orally with the aid of a syringe and a rat oral feeding needle. The blood samples were drawn by retro-orbital venous plexus puncture with the aid of bleeding capillary tubes. The blood samples were centrifuged at $3400 \mathrm{rpm}$ for $10 \mathrm{~min}$ into separate plasma. The supernatant (plasma) was collected and stored at $-80{ }^{\circ} \mathrm{C}$ until analysis.

The samples were taken according to the regulatory guidelines. The rats were anesthetized in an anesthetic chamber using diethyl ether each time before the collection of the blood samples. At various time intervals $\sim 250 \mu \mathrm{L}$ of blood was collected in $0.5 \mathrm{~mL}$ Eppendorf tubes containing $25 \mu \mathrm{L}$ anticoagulant ( $3.4 \% \mathrm{w} / \mathrm{v}$ sodium citrate). A validated HPLC method was used for the analysis. The RLX detection was performed at $289 \mathrm{~nm}$, using an ZORBAX SB-C8 $(5 \mu \mathrm{m}, 4.6 \times 150 \mathrm{~mm})$ (Agilent Technologies Inc., Santa Clara, CA, USA) analytical column. The mobile phase composition was 63:37 (v/v) of pH 4.5 $20 \mathrm{mM}$ ammonium acetate buffer (adjusted with acetic acid)/acetonitrile at a flow rate of $1.0 \mathrm{~mL} / \mathrm{min}$. The plasma samples $(0.1 \mathrm{~mL})$ were transferred to $1.5 \mathrm{~mL}$ Eppendorf followed by the addition of $150 \mu \mathrm{L}$ acetonitrile and $50 \mu \mathrm{L}$ mobile phase premix to precipitate the plasma proteins. The above mixture was vortexed for $5 \mathrm{~min}$ and centrifuged at 10,000 rpm for $10 \mathrm{~min}$. Then, $50 \mu \mathrm{L}$ of the supernatant was injected into the column. The calibration curves for the RLX in plasma were drawn every time 
during the analysis using the lower quantifying concentration $150 \mathrm{ng} / \mathrm{mL}$, the middle quantifying concentration $600 \mathrm{ng} / \mathrm{mL}$ and the higher quantifying concentration $1300 \mathrm{ng} / \mathrm{mL}[11,33]$.

\section{Results and Discussion}

\subsection{Particle Size and Polydispersity Index}

The size of the nano formulations is an important factor that affects the stability, lymphatic transport and bioavailability [34-37]. Li et al. had reported that the lowest size NLC (100 nm) in their study was the most stable. Though all NLC sizes $(100,200$ and $300 \mathrm{~nm})$ could rapidly penetrate the duodenum versus the later part of the intestine (jejunum, ileum and colon), however, smaller NLCs $(100 \mathrm{~nm})$ showed the highest pharmacokinetics parameters $\left(C_{\max }\right.$ and Area under the curve (AUC)). Herein, the particle size of the NLCs is presented as the Z-average, d50, d90 and d95. The Z-average depicts the mean hydrodynamic diameter of the particles. The other diameters in this study (d50, d90 and d95) depict the percentage of undersized particles. Table 2 presents the particle characteristics of the NLC formulations and Figure 1 shows the effect of the P407 concentration on the formulation characteristics. It revealed that the formulation composition and the process variables like the surfactant concentration, homogenization, sonication and the amount of oleic acid significantly influenced the particle sizes. Introducing the homogenization step for $3 \mathrm{~min}$ in addition to the magnetic stirring significantly reduced the average particle size of NLC. The homogenization helped in reducing the particle size and making the pre-emulsion more homogeneous. The homogenization alone was not enough to get the further reduction in particle size and PDI. It was possible to achieve only by increasing the time of homogenization and the homogenization rpm or else by the use of ultrasonication. However, the homogenization parameters i.e., the time and rpm, were difficult to manage because of the foam generation during homogenization.

Table 2. Particle characteristics of the various NLC formulations for optimization.

\begin{tabular}{ccccccc}
\hline Code & $\begin{array}{c}\text { d-avg } \\
(\mathbf{d} . \mathbf{n m})\end{array}$ & PDI & $\begin{array}{c}\text { d50 } \\
\text { (d.nm) }\end{array}$ & $\begin{array}{c}\text { d90 } \\
(\mathbf{d} . \mathbf{n m})\end{array}$ & $\begin{array}{c}\text { d95 } \\
(\mathbf{d} . \mathbf{n m})\end{array}$ & $\begin{array}{c}\text { Zeta Potential } \\
\mathbf{( m V )}\end{array}$ \\
\hline NLC 1 & 124 & 0.191 & 115 & 227 & 267 & -13.2 \\
NLC 2 & 310 & 0.233 & 280 & 521 & 621 & +8.71 \\
NLC 3 & 120 & 0.293 & 97 & 209 & 270 & +14.4 \\
NLC 4 & 142 & 0.259 & 123 & 250 & 302 & +12.3 \\
NLC 5 & 132 & 0.224 & 124 & 240 & 288 & +14.8 \\
NLC 6 & 179 & 0.305 & 120 & 271 & 329 & +11.7 \\
NLC 7 & 115 & 0.380 & 173 & 492 & 659 & +15.2 \\
NLC 8 & 182 & 0.319 & 255 & 572 & 689 & +17.8 \\
NLC 9 & 247 & 0.383 & 342 & 790 & 1100 & +15.4 \\
\hline
\end{tabular}

The extensive foam generation during the homogenization was observed at a higher rpm, which lead to larger visible particles and aggregates floating in the formulation. Therefore, the homogenization followed by sonication was used instead of only the sonication or homogenization. The ultrasonication process was used for a further size reduction and to reduce the PDI. Surajit Das et al. have shown that an increase in sonication time caused a decrease in the particle size to a certain extent [38]. However, after a certain time of sonication, the particle size did not change drastically. Herein, we studied the effect of sonication time for $10 \mathrm{~min}$ and $20 \mathrm{~min}$ for the optimized formulation. There was no significant difference in the particle size between the NLCs formulated with $10 \mathrm{~min}$ sonication and those with $20 \mathrm{~min}$ sonication. However, a slight increase in the particle size was observed with a higher sonication time. This can be attributed to the water loss as a cause of evaporation due to the heat generation during sonication for $20 \mathrm{~min}$. Furthermore, an increment in surfactant concentration during the formulation as a cause of evaporation can also affect the particles characteristics. Therefore, we suggest that a longer sonication time should be avoided. The smaller size (100 $\mathrm{nm}$ or less) NLCs 
could also be produced by the use of other methods such as solvent diffusion $[31,36]$, modifying the composition [31] and the use of microfluidic devices [39].

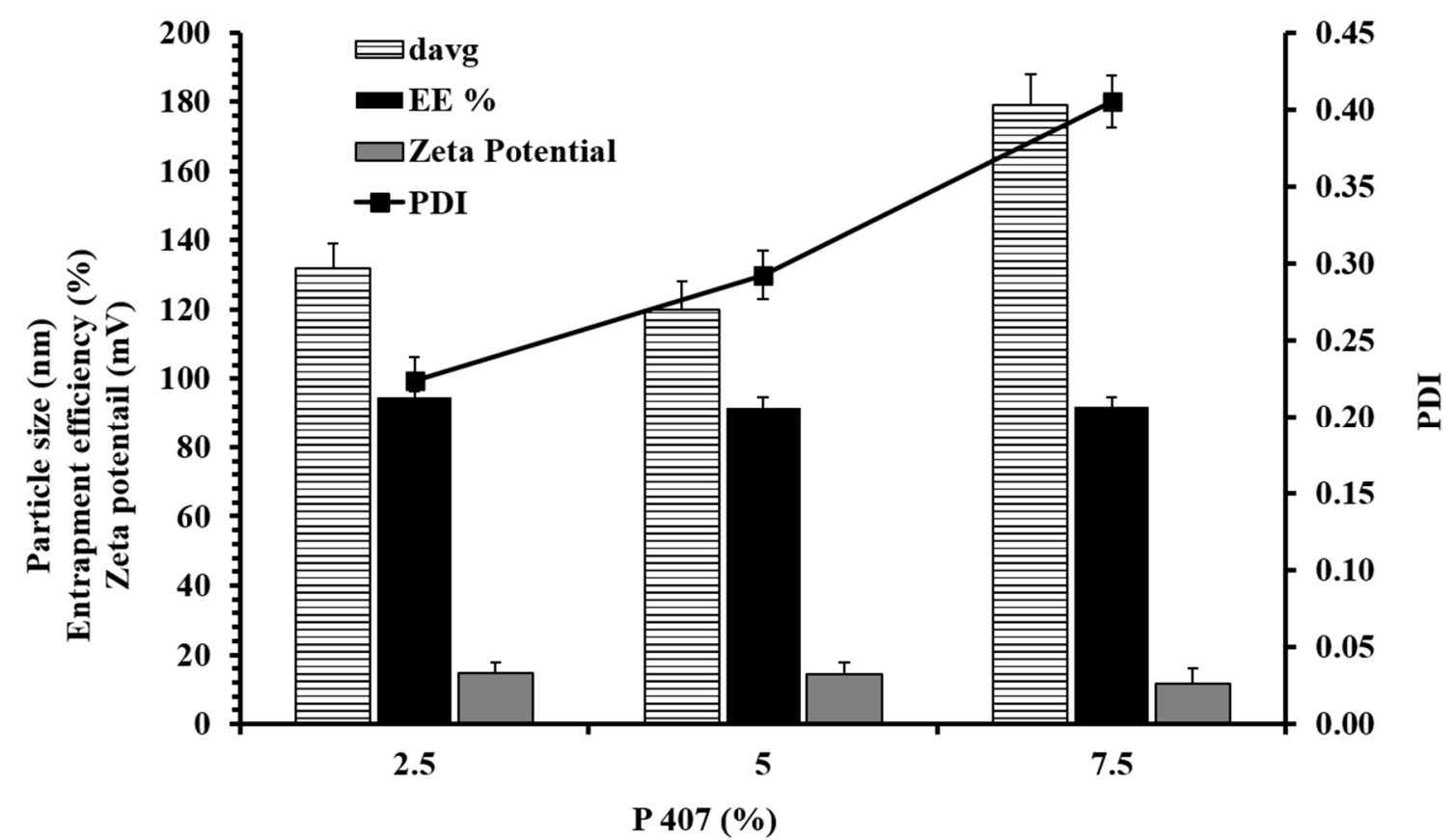

Figure 1. Effect of surfactant concentration on particle characteristics (d-avg, PDI, zeta potential) and percentage of entrapment efficiency (\% EE).

The particle size was found to decrease when the oleic acid amount varied between $9.1 \%$ and $30 \%$ to replace a part of the glyceryl behenate (solid lipid) amount. The decrease in particle size with an increase in oleic acid could be attributed to the reduction in the interfacial tension in the presence of oleic acid. Uprit, S. et al. have previously shown that the amount oleic acid in the NLCs can have an impact on the viscosity and interfacial tension, because of which it can form smaller particles [40]. The P407 concentration was also found to affect the particle size at a higher concentration. There was a significant increase in the particle size when the P407 concentration was increased from $2.5 \%$ to $7.5 \%$ during the pre-emulsion formation. Sanjula B. et al. have also reported that an increase in poloxamer concentration in SLNs can reduce the lymphatic uptake as a cause of an increase in particle size [23]. The increase in particle size can be attributed to the aggregation of particles at a higher P407 concentration.

The PDI is also an important parameter to interpret the distribution of particle size. It was utilized to optimize the NLC formulation and for interpreting the storage stability of NLCs. For the PDI system from 0 to 1 , the PDI close to 0 shows a monodisperse dispersion while the value 1 shows a wide distribution. The PDI $<0.2$ is considered as a narrow size distribution for nano formulations. The results showed that the PDI can be affected by homogenization rpm, time of homogenization and sonication, method of formulation, temperature, etc. The homogenization step incorporated before ultrasonication significantly reduced the PDI as compared to the NLCs prepared without homogenization. The PDI was found to increase with the increase in sonication time from 10 to $20 \mathrm{~min}$. This can be attributed to changes occurring during the NLC preparation like an increment in the concentration of the surfactant as a cause of water evaporation and heat generation leading to changes in the distribution of RLX in the aqueous and lipidic phase. The increase in surfactant concentration also increased the PDI of the NLCs. There was no direct correlation between the PDI and the percentage of oleic acid (see Figures 1 and 2). Hence, considering the particle sizes and the PDI, the optimum NLC formulation was NLC 3, which was carried forward for stability and pharmacokinetics studies. 


\subsection{Zeta Potential}

The zeta potential represents the charge of the particles. It indicates the degree of repulsion between similarly charged particles in the dispersion. This repulsion force helps in predicting the physical stability of the formulation [41,42]. Therefore, the zeta potential was a useful parameter for optimizing the formulation. The RLX suspension in water showed $+25 \mathrm{mV}$ zeta potential while the placebo formulation showed $-13.7 \mathrm{mV}$ and all the other NLCs also showed positive zeta potential. The negative zeta potential in the placebo could be attributed to the surface-ionized oleic acid and the positive zeta potential in the formulation can be attributed to the drug-enriched shell of RLX. This phenomenon of a drug-enriched shell has been reported previously. The core of the lipid nanocarriers forms when the temperature of the dispersion is reduced to the recrystallization temperature of the lipid, and due to this the drug concentrates in the still liquid outer shell of the SLN $[38,42,43]$. Therefore, the drug-enriched outer shell and zwitterion nature of RLX support the positive charge of the particles.

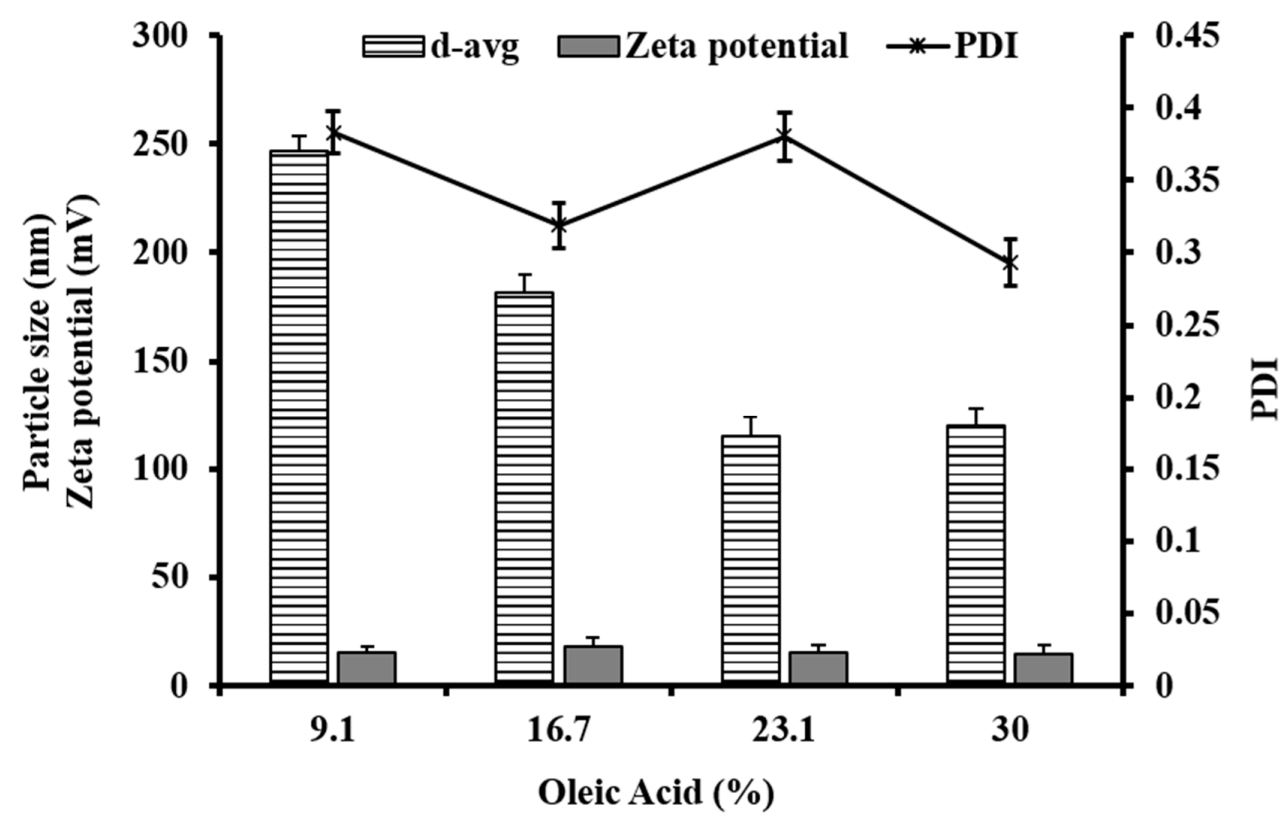

Figure 2. Effect of the amount of oleic acid $(\% w / w)$ on the NLC particle characteristics (d-avg, zeta potential and PDI).

The results showed that (see Figure 2) there was no significant change in the zeta potential with the change of surfactant concentration from $2.5 \%$ to $7.5 \%$. However, a slight decrease (not significant) in the zeta potential in the $7.5 \%$ NLCs as compared to the $2.5 \%$ and $5 \%$ NLCs was observed. This can also be correlated to the higher particle size (see Figure 2) in the $7.5 \%$ NLCs than the $2.5 \%$ and $5 \%$ NLCs. There was no specific correlation between the zeta potential of the NLCs in relation to the sonication time and the oleic acid content.

\subsection{Entrapment Efficiency}

There was no significant change in the \% EE with the change in the surfactant concentration (see Table 3). This can be attributed to the efficient drug loading with enough amount of lipid, which enables the available RLX to be mostly loaded into the NLCs. The results showed that the \% EE of the NLCs was not affected by changing the sonication time from 10 to 20 min, while increasing the P407 concentration reduced the \% EE of RLX (Table 3). The reduction in the \% EE was obvious as the drug-apparent solubility increases with the increase in the surfactant concentration. However, the optimum amount of surfactant is essential as it helps in getting smaller-size NLCs and provides stability while also retaining good entrapment efficiency. Pandita et al. have shown that poloxamer 188 concentration beyond $1.5 \% \mathrm{w} / \mathrm{v}$ decreased the $\%$ EE of paclitaxel, while $0.5 \%$ to $1.5 \% \mathrm{w} / \mathrm{v}$ surfactant 
increased the \% EE [44]. In contrast, Pezeshki et al. showed an increase in the \% EE of Vitamin A palmitate with the increase in \% P407; however, the stability of the NLCs was reduced with a higher surfactant concentration [45].

Table 3. In vitro raloxifene hydrochloride (RLX) release and EE (\%) of the selected NLC formulations. NLC 3, 5 and 6 are with varied surfactant concentrations while NLC 4 is with varied sonication time. $\mathrm{EE}(\%)$ - percentage entrapment efficiency; CR (\%)-percentage cumulative release.

\begin{tabular}{ccccc}
\hline Code & $\begin{array}{c}\text { EE } \\
(\mathbf{\%})\end{array}$ & $\begin{array}{c}\text { Free Drug } \\
\mathbf{( \% )}\end{array}$ & $\begin{array}{c}\text { CR } \\
\mathbf{( \% )}\end{array}$ & $\begin{array}{c}\text { CR } \\
(\mathbf{\%}, \text { Excluding Free Drug) }\end{array}$ \\
\hline NLC 3 (5\% P407) & 91.71 & 8.29 & 28.48 & 20.19 \\
NLC 6 (7.5\% P407) & 88.13 & 11.87 & 30.16 & 18.29 \\
NLC 5 (2.5\% P407) & 94.51 & 5.49 & 18.68 & 13.19 \\
NLC 4 (5\% P407) & 92.07 & 7.93 & 30.71 & 22.79 \\
\hline
\end{tabular}

\subsection{In Vitro Drug Release}

The NLCs prepared with different surfactant concentrations were analyzed for cumulative drug release to measure the amount of RLX release in the GIT $\mathrm{pH}$ conditions. The \% CR of RLX was found to be the lowest for the formulation made with $2.5 \%$ surfactant and highest for the formulation made with $7.5 \%$ surfactant (Table 3 ).

All the tested formulations show bi-phasic release, where the initial burst release of RLX can be seen until $1 \mathrm{~h}$ followed by slow release. The bi-phasic release of drugs from the SLNs and NLCs prepared using hot homogenization has also been reported earlier [11,46]. The initial burst release can be attributed to the dissolution of both the free RLX and RLX release from the drug-enriched outer shell. The second phase i.e., the slow release, is attributed to the core of the NLCs. The \% CR of RLX from the NLCs was no more than $30 \%$ after $12 \mathrm{~h}$ incubation for all the P407-tested concentrations (See Figure 3). The minimal release of RLX into the GIT pH conditions will ensure the higher bioavailability of RLX via NLCs. The un-released RLX from the NLCs can be absorbed via the lymphatic transport of NLCs that significantly enhances the bioavailability of RLX while also surpassing the Pgp efflux in the intestine.

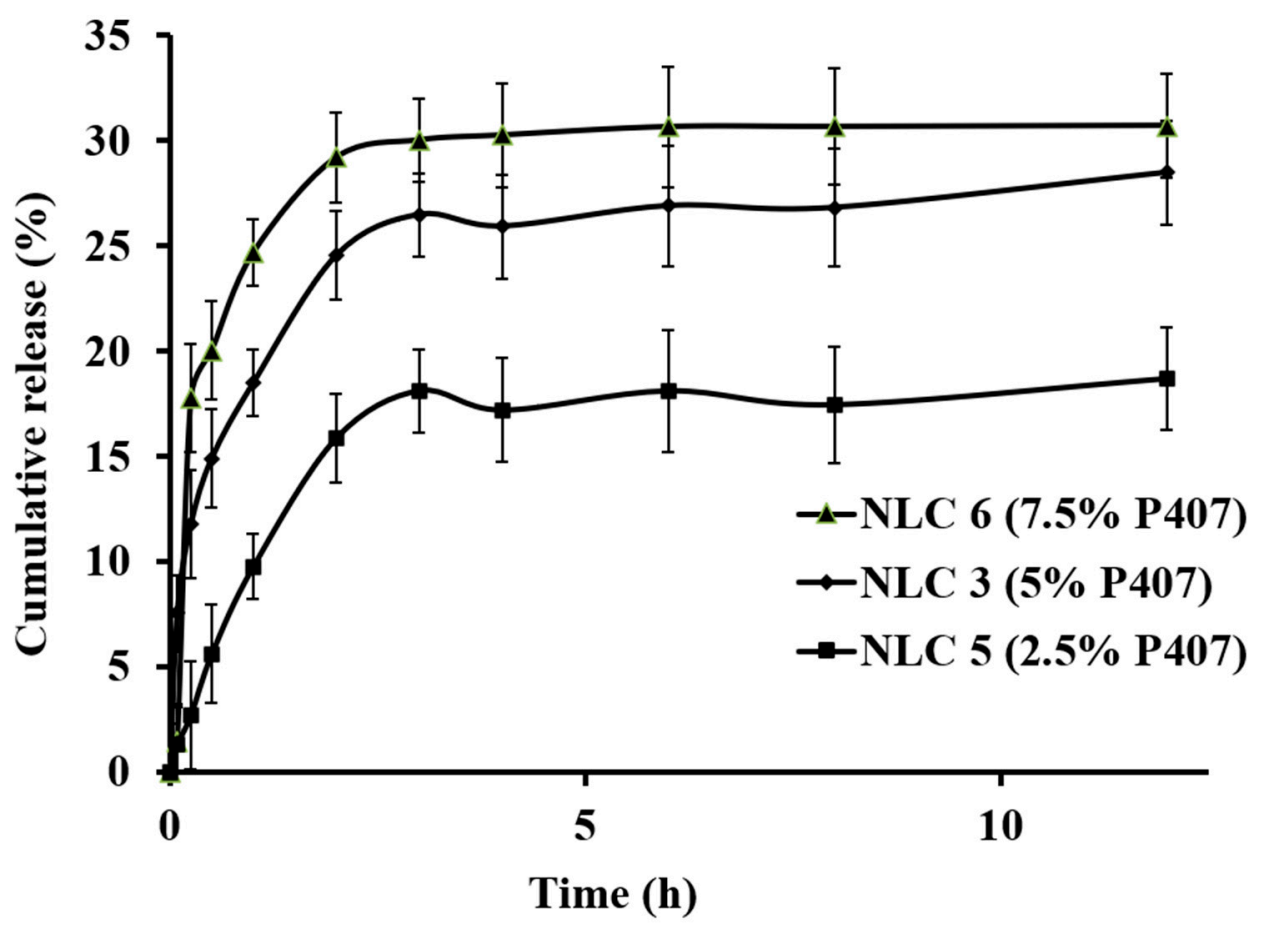

Figure 3. Effect of the P407 concentration on the percentage cumulative release of RLX from the NLCs. 


\subsection{Differential Scanning Calorimetry}

The DSC thermogram of the formulation ingredients and the mixture of ingredients is shown in Figure 4. The sharp peak in the thermogram of RLX at $271{ }^{\circ} \mathrm{C}$ corresponds to the melting peak of the RLX crystals. The RLX peak remains unchanged in the physical mixture of glyceryl behenate and RLX. However, the endothermic peak height of RLX was reduced and shifted to $160^{\circ} \mathrm{C}$ in the melt dispersion of lipid with 10\% oleic acid and the sharp peak disappeared in the melt dispersion having $30 \%$ oleic acid. A broad dip in the baseline was seen in the mixture having $30 \%$ oleic acid. The shift of the peak and the peak broadening shows the change in the degree of crystallinity. Therefore, it can be concluded that the crystallinity of RLX was significantly reduced due to the dispersion of raloxifene in the lipid-oil matrix. The change in the degree of the crystallinity of glyceryl behenate can also be seen by comparing the heat of enthalpy per gram. The measured heat of enthalpy (in J/g) for pure glyceryl behenate, $10 \%$ oleic acid mixture and $30 \%$ oleic acid mixture was $-75.89,-63.74$ and -51.58 , respectively. The decrease in the heat of enthalpy per gram of lipid shows a decrease in the crystallinity of the lipid in the presence of the oleic acid. Similarly, the peak broadening was also seen for glyceryl behenate in the melt dispersion which showed the reduction in crystallinity of glyceryl behenate. It can be attributed to the presence of oleic acid in the melt dispersion which helps in preventing the recrystallization of glyceryl behenate as well as RLX. Therefore, the shift of the peak and reduction in peak height whether in lipid or drug can be attributed to the matrix which was composed of the mixture of lipids.

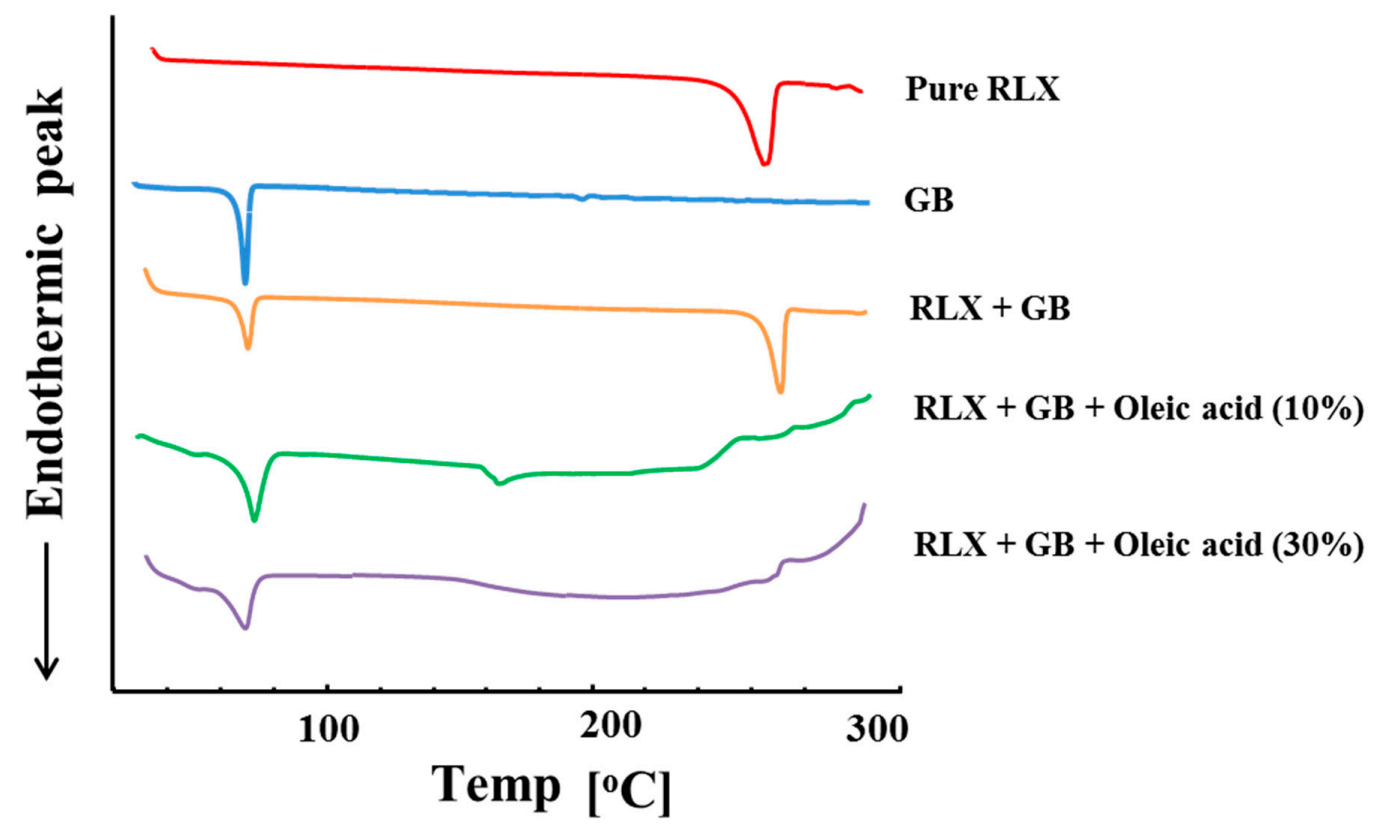

Figure 4. Differential scanning calorimetry (DSC) thermograms of the physical mixture of ingredients used in the NLCs. GB: glyceryl behenate; RLX: raloxifene hydrochloride.

\subsection{Pharmacokinetics}

The NLC 3 was carried forward for the in vivo study as it showed the optimum average size (lowest), PDI and zeta potential. The pharmacokinetic parameters of the RLX suspension, RLX-NLC (NLC 3) is presented in Table 4 and its pharmacokinetic profile in Figure 5. A significant enhancement in the oral bioavailability by 3.1-fold with RLX-NLC was observed as compared to the RLX suspension. This can be attributed to the low drug release in the GIT as supported by the in vitro drug release and absorption of both the free drug and NLCs via different absorption pathways [23,47]. The absorption pathways for the NLCs could be through the lymphatic uptake by M cells in the intestine. In the earlier study from our group, based on the uptake study of the SLN produced from glyceryl behenate, 
it was shown that clathrin- and caveolae-mediated endocytosis contributed to the uptake from rat intestine. Furthermore, the passive drug diffusion through the micellar absorption could also be contributing to the drug's bioavailability enhancement. Since the cumulative drug release from the formulation in the $\mathrm{pH} 1.2$ and $\mathrm{pH} 6.8$ buffers was less than $30 \%$, the lymphatic pathway could therefore be the major absorption route for the bioavailability enhancement of RLX-NLC. The peak plasma concentration for RLX-NLC was twice as much as that for the RLX suspension. The time to reach maximum plasma concentration was the same for the RLX suspension and the RLX-NLC but the mean residence time (MRT) for the NLCs was more than twice of that for the compared RLX suspension. Furthermore, the clearance of the RLX in rats given RLX suspension was higher than that of the rats given RLX-NLC. The decrease in clearance, increase in MRT, increase of plasma $t_{1 / 2}$ and increase in plasma $\mathrm{C}_{\max }$ supported the oral bioavailability enhancement and the potential for better therapeutic treatment. Recently, Hosny et al. reported the enhancement in the clinical bioavailability of RLX using NLCs [48].

Table 4. Pharmacokinetic parameters of RLX in the oral administration of the optimized NLC formulation (NLC 3) and the RLX suspension in female Wistar rats. ${ }^{*} p<0.05$.

\begin{tabular}{ccc}
\hline Parameter & RLX Suspension & RLX-NLC \\
\hline $\mathbf{C}_{\max }(\mathbf{n g} / \mathbf{m L})$ & $181.71 \pm 17.83$ & $391.35 \pm 32.53^{*}$ \\
$\mathbf{T}_{\max }(\mathbf{h})$ & $2.00 \pm 0.32$ & $1.00 \pm 0.25^{*}$ \\
$\mathbf{M R T}(\mathbf{h})$ & $13.00 \pm 1.17$ & $19.09 \pm 1.05^{*}$ \\
$\mathbf{A U C}_{(\mathbf{0 - t})}(\boldsymbol{\mu g} . \mathbf{h} / \mathbf{m L})$ & $2.49 \pm 0.23$ & $7.71 \pm 0.34^{*}$ \\
$\mathbf{t}_{\mathbf{1} / \mathbf{2}}(\mathbf{h})$ & $13.21 \pm 1.35$ & $20.00 \pm 2.13^{*}$ \\
$\mathbf{F}_{\text {rel }}$ & - & 3.19 \\
\hline
\end{tabular}

MRT: Mean residence time; $\mathrm{AUC}_{(0-\mathrm{t})}$ : Area under the curve between 0 to time ' $\mathrm{t}$ '.

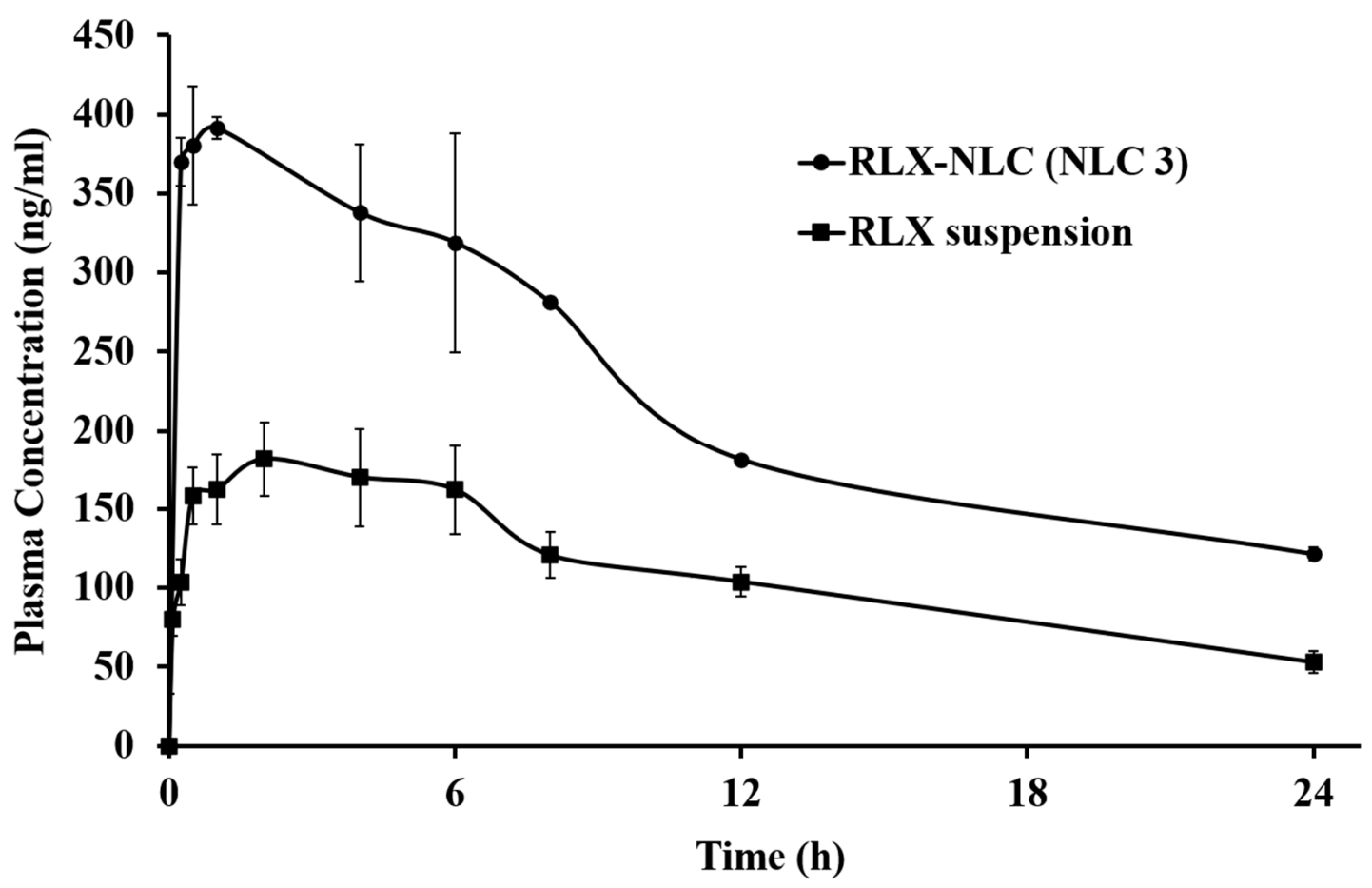

Figure 5. Pharmacokinetic profile of RLX for $24 \mathrm{~h}$ after oral administration of the optimized NLC formulation (NLC 3) and the RLX suspension in female Wistar rats. Data are given as the mean \pm SD $(n=3)$. 


\subsection{Stability Studies}

The optimized NLC formulation (i.e., NLC3) that had a balance of low size, narrow size distribution, enough zeta potential and good entrapment efficiency, was accessed for stability, and the same formulation was also studied for bioavailability enhancement (Figure 5). The stability was accessed based on changes in particle characteristics (Figures 6 and 7) and changes in the \% EE (Figure 8). The slight increase in PDI and particle size (Figure 6) while the slight decrease in zeta potential and \% EE (Figure 8A) were observed over a 6-month storage period at $4{ }^{\circ} \mathrm{C}$. However, significant changes were observed in NLCs stored at room temperature $\left(25^{\circ} \mathrm{C} \pm 2{ }^{\circ} \mathrm{C}\right.$ and $60 \% \pm 5 \%$ RH) (Figures 7 and 8B).
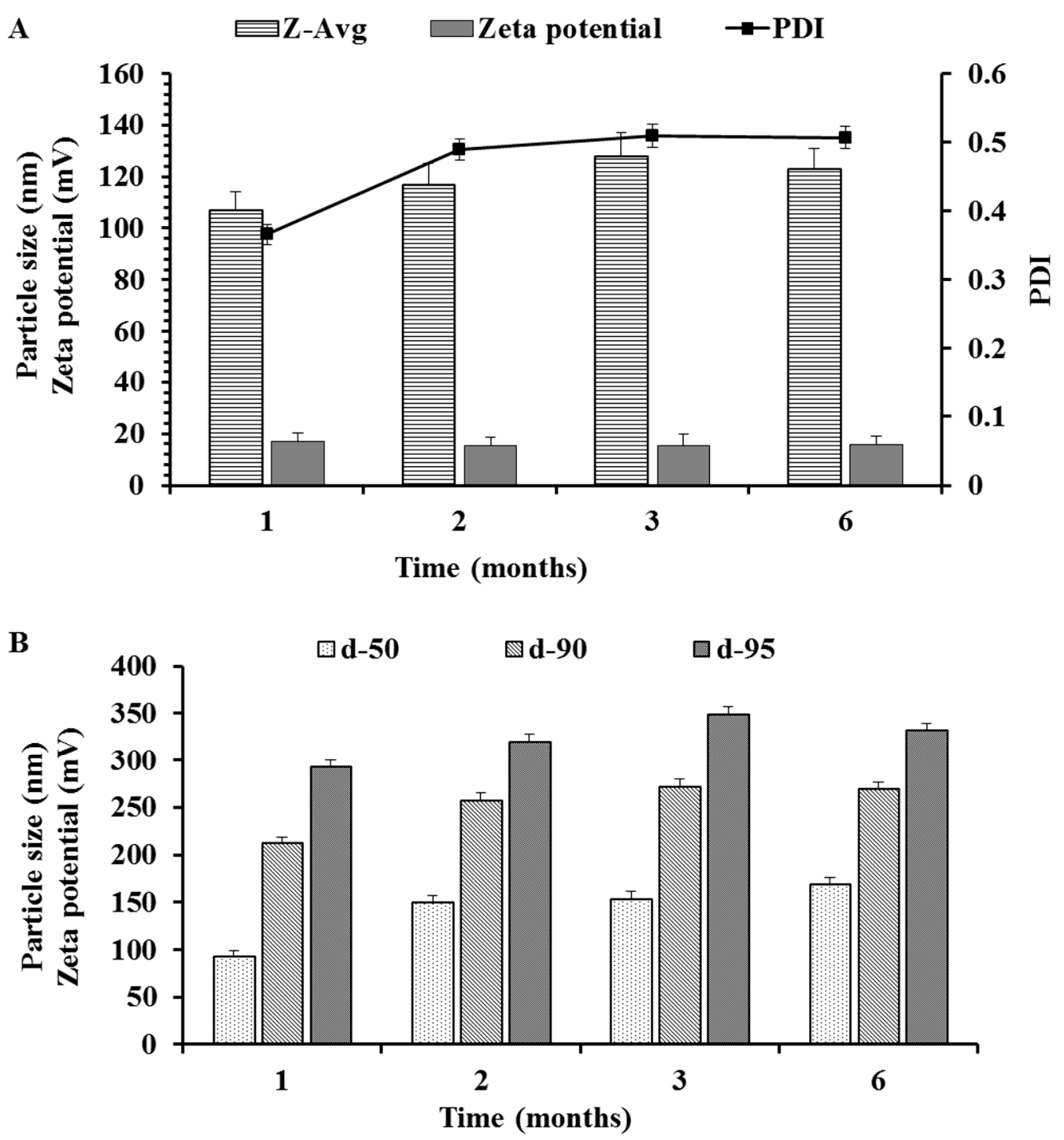

Figure 6. Stability of the particles as a function of time at $4{ }^{\circ} \mathrm{C}$. (A) Particle size as the Z-average, polydispersity index (PDI) and zeta potential. (B) Particle sizes of d50, d90, d95.

If only Z-average is recorded for stability, then a significant change in particle characteristics cannot be predicted because some percentage of bigger particles will not affect the Z-average. However, the difference can be easily seen when comparing other particle characteristics such as undersized particle sizes (d50, d90 and d95), zeta potential, PDI and \% EE. The PDI, d90 and d95 (Figure 7) were significantly increased over the period of 6 months storage at room temperature while the \% EE (Figure 8 ) and the zeta potential (Figure 7) were decreased. This can be attributed to the expulsion of 
the drug with the oozing of oleic acid that simultaneously causes a decrease in zeta potential, as well causing the aggregation of particles and an increase in the PDI. The effect of the storage conditions on the \% EE is shown in Figure 8. The reduction in \% EE was seen at both storage conditions, but it was lesser in the NLCs stored at $4{ }^{\circ} \mathrm{C}$ than NLCs stored at room temperature. The drug expulsion from the lipid nanocarriers upon ageing has been reported earlier, which is due to the crystallization of the solid lipid matrix causing the expulsion of the drug subsequently leading to a reduction in the \% EE $[49,50]$. Therefore, to estimate the shelf-life of the optimized NLCs, the time taken to reach $90 \%$ of initial $\%$ $\mathrm{EE}\left(\mathrm{t} 90_{\mathrm{EE}}\right)$ was considered as a stability indicator. As predicted and shown in Figure 8 , the \% EE of the NLCs stored at $4{ }^{\circ} \mathrm{C}$ after 6 months ranged (at 95\% confidence interval (C.I.)) from $99.11 \%$ (upper C.I.) to $93.5 \%$ (lower C.I.), with a mean of $96.18 \%$ while for NLCs stored at room temperature the $\%$ EE ranged from $92.87 \%$ (upper C.I.) to $88.16 \%$ (lower C.I.), with a mean of $90.51 \%$. The NLCs being more stable at $4{ }^{\circ} \mathrm{C}$ can be attributed to the reduced expulsion of the drug because of the changes that occurred in the crystal lattice of the glyceryl behenate. In addition, the oleic acid oozing out would be least at $4{ }^{\circ} \mathrm{C}$ because the storage temperature was significantly below the congealing temperature of the oleic acid. In addition, the presence of oleic acid also prevents the expulsion of RLX. Therefore, we suggest the storage of NLC at $4{ }^{\circ} \mathrm{C}$ for better stability.
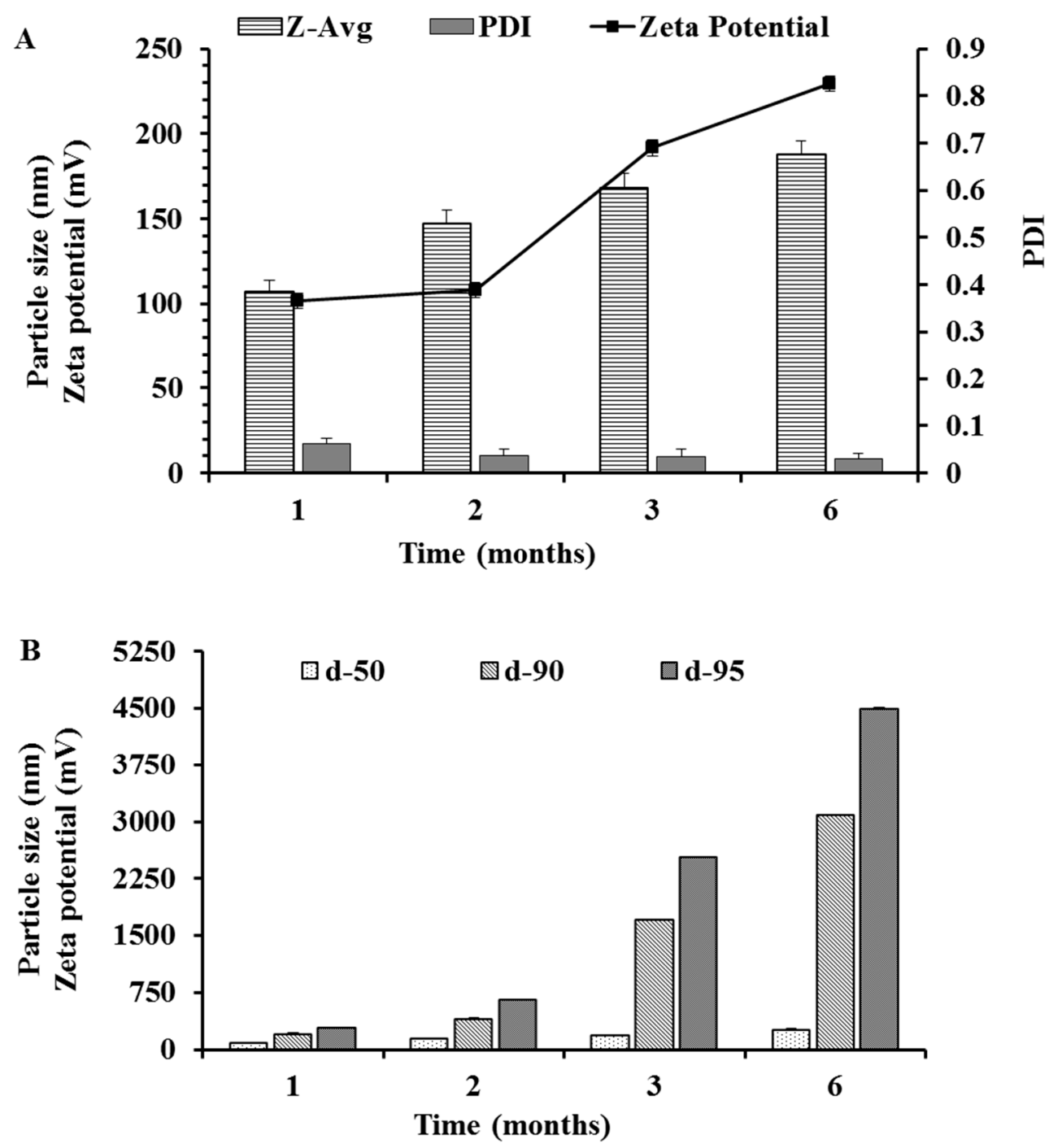

Figure 7. Stability of the particle as a function of time at room temperature. (A) Particle sizes as the Z-average, PDI and zeta potential. (B) Particle sizes of d50, d90, d95. 


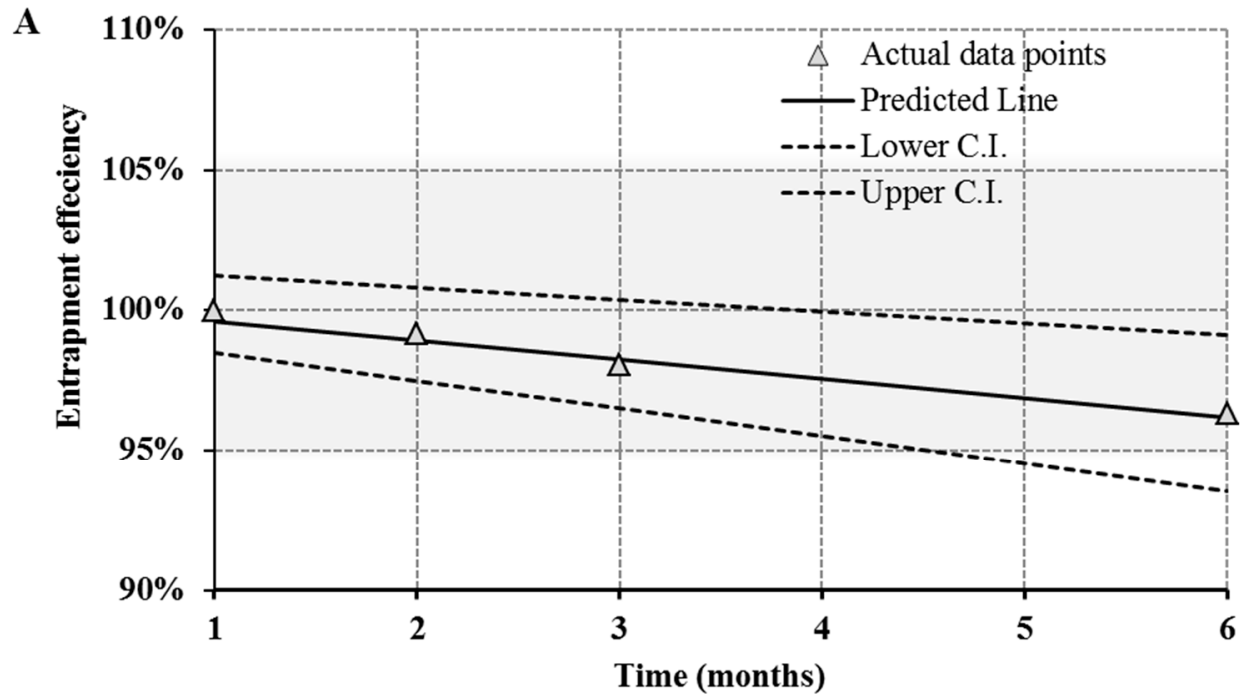

B

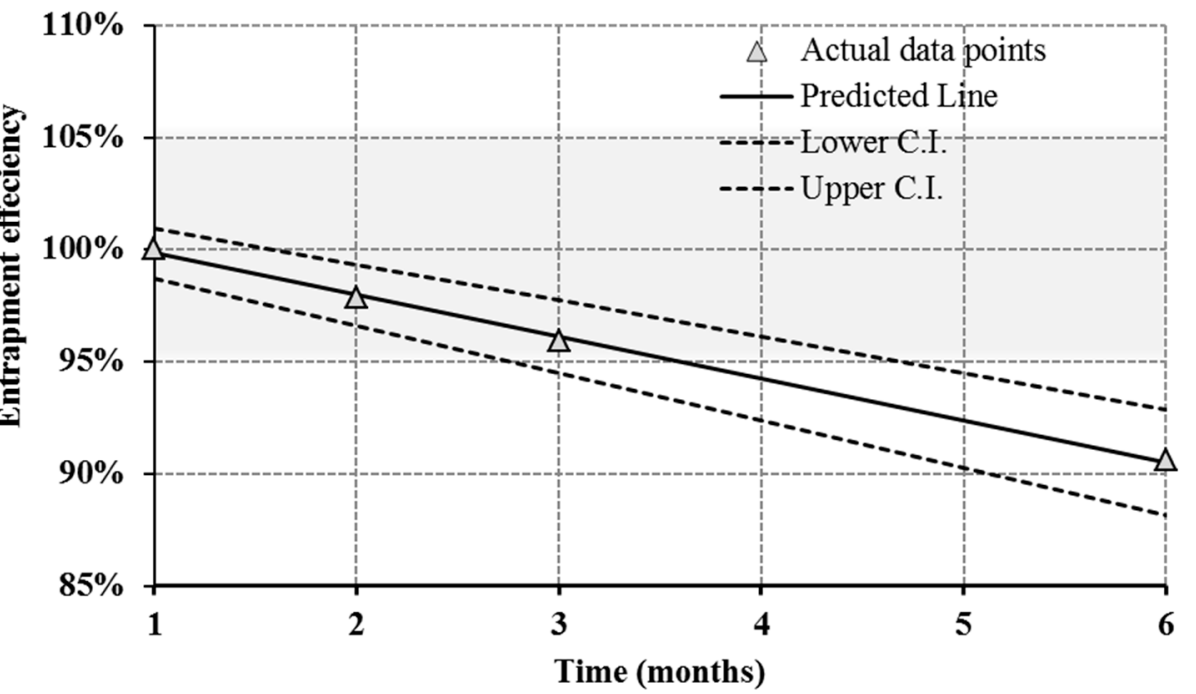

Figure 8. Shelf-life estimation of the RLX-solid lipid nanoparticles (SLNs) (A) at $4{ }^{\circ} \mathrm{C}$ and (B) at $25{ }^{\circ} \mathrm{C}$ $\pm 2{ }^{\circ} \mathrm{C}$ and $60 \% \pm 5 \% \mathrm{RH}$. Dotted line shows the $95 \%$ confidence interval limits.

\section{Conclusions}

The nanosized RLX-loaded NLCs were prepared in the study using a combination of hot homogenization and sonication, with a high $(>90 \%)$ encapsulation efficiency. The calorimetric study showed a reduction in the crystallinity of RLX in the dispersion of lipid-oil. The processing parameters like the amount of oleic acid, sonication time, homogenization and P407 concentration, can all affect the NLC characteristics including the particle size, zeta potential, $\% \mathrm{EE}, \% \mathrm{CR}$ and the NLC stability. The RLX-NLC (120 nm average size, +14 zeta potential) based on glyceryl behenate and oleic acid showed potential to enhance the oral bioavailability of RLX in rats. RLX-NLC also improved the pharmacokinetic parameters of RLX. The RLX-NLC were physically stable and retained the RLX encapsulation ( $>90 \%$ from initial \% EE) at cold conditions for over 6 months of storage. Overall, the RLX-NLC can be a potential therapeutic delivery strategy in osteoporosis while also providing a better shelf life.

Author Contributions: Conceptualization, A.M.; data curation, H.K. and S.M.; formal analysis, A.M., H.K. and S.M.; funding acquisition, P.R.R.; investigation, A.M.; methodology, H.K. and S.M.; project administration, A.M. and P.R.R.; resources, A.M. and P.R.R.; software, A.M., P.R.R., H.K. and S.M.; supervision, P.R.R.; visualization, A.M. and H.K.; writing-original draft, A.M. and H.K.; writing-review and editing, A.M., P.R.R. and H.K. All authors have read and agreed to the published version of the manuscript. 
Funding: This research was funded by Union Grants Commission (UGC), New Delhi, India, grant number Ref No. 39-176/2010 (SR).

Acknowledgments: The authors wish to acknowledge the University Grants Commission (UGC), India, for supporting this research work through a Major Research Project (Ref No. 39-176/2010 (SR)).

Conflicts of Interest: The authors declare no conflict of interest.

\section{References}

1. Prevention and management of osteoporosis. World Health Organ Tech. Rep. Ser. 2003, 921, 1-164.

2. Francis, R.M. An Atlas of Osteoporosis: The Encyclopedia of Visual Medicine Series. J. R. Soc. Med. 1993, 86, 682.

3. Kanis, J. Assessment of Osteoporosis at the Primary Health Care Level; Technical Report; World Health Organization Collaborating Centre for Metabolic Bone Diseases: Geneva, Switzerland, 2008; pp. 6-9.

4. Johnell, O.; Kanis, J.A. An estimate of the worldwide prevalence and disability associated with osteoporotic fractures. Osteoporos Int. 2006, 17, 1726-1733. [CrossRef] [PubMed]

5. Thiebaud, D.; Secrest, R.J. Selective estrogen receptor modulators: Mechanism of action and clinical experience. Focus on raloxifene. Reprod. Fertil. Dev. 2001, 13, 331-336. [CrossRef]

6. Lufkin, E.G.; Whitaker, M.D.; Nickelsen, T.; Argueta, R.; Caplan, R.H.; Knickerbocker, R.K.; Riggs, B.L. Treatment of established postmenopausal osteoporosis with raloxifene: A randomized trial. J. Bone Miner. Res. 1998, 13, 1747-1754. [CrossRef]

7. Pinsky, P.F.; Miller, E.A.; Heckman-Stoddard, B.M.; Minasian, L. Breast Cancer Characteristics and Survival among Users versus Nonusers of Raloxifene. Cancer Prev. Res. 2020, 13, 83-90. [CrossRef]

8. Amidon, G.L.; Lennernas, H.; Shah, V.P.; Crison, J.R. A theoretical basis for a biopharmaceutic drug classification: The correlation of in vitro drug product dissolution and in vivo bioavailability. Pharm. Res. 1995, 12, 413-420. [CrossRef]

9. Gluck, O.; Maricic, M. Skeletal and nonskeletal effects of raloxifene. Curr. Osteoporos. Rep. 2003, 1, 123-128. [CrossRef]

10. Trdan Lusin, T.; Mrhar, A.; Stieger, B.; Kullak-Ublick, G.A.; Marc, J.; Ostanek, B.; Zavratnik, A.; Kristl, A.; Berginc, K.; Delic, K.; et al. Influence of hepatic and intestinal efflux transporters and their genetic variants on the pharmacokinetics and pharmacodynamics of raloxifene in osteoporosis treatment. Transl. Res. 2012, 160, 298-308. [CrossRef]

11. Ravi, P.R.; Aditya, N.; Kathuria, H.; Malekar, S.; Vats, R. Lipid nanoparticles for oral delivery of raloxifene: Optimization, stability, in vivo evaluation and uptake mechanism. Eur. J. Pharm. Biopharm. 2014, 87, 114-124. [CrossRef]

12. Findlay, S.M. Drug Delivery Markets—An Outlook. Available online: https://www.frost.com/sublib/displaymarket-insight.do?id=134287829 (accessed on 26 March 2016).

13. Lu, R.; Liu, S.; Wang, Q.; Li, X. Enhanced bioavailability of raloxifene hydrochloride via dry suspensions prepared from drug/HP-beta-cyclodextrin inclusion complexes. Pharmazie 2015, 70, 791-797. [CrossRef] [PubMed]

14. Ye, Y.; Zhang, T.; Li, W.; Sun, H.; Lu, D.; Wu, B.; Zhang, X. Glucose-Based Mesoporous Carbon Nanospheres as Functional Carriers for Oral Delivery of Amphiphobic Raloxifene: Insights into the Bioavailability Enhancement and Lymphatic Transport. Pharm. Res. 2016, 33, 792-803. [CrossRef] [PubMed]

15. Velpula, A.; Jukanti, R.; Janga, K.Y.; Sunkavalli, S.; Bandari, S.; Kandadi, P.; Veerareddy, P.R. Proliposome powders for enhanced intestinal absorption and bioavailability of raloxifene hydrochloride: Effect of surface charge. Drug Dev. Ind. Pharm. 2013, 39, 1895-1906. [CrossRef]

16. Tran, T.H.; Poudel, B.K.; Marasini, N.; Woo, J.S.; Choi, H.G.; Yong, C.S.; Kim, J.O. Development of raloxifene-solid dispersion with improved oral bioavailability via spray-drying technique. Arch. Pharm. Res. 2013, 36, 86-93. [CrossRef]

17. Tran, T.H.; Poudel, B.K.; Marasini, N.; Chi, S.C.; Choi, H.G.; Yong, C.S.; Kim, J.O. Preparation and evaluation of raloxifene-loaded solid dispersion nanoparticle by spray-drying technique without an organic solvent. Int. J. Pharm. 2013, 443, 50-57. [CrossRef] [PubMed] 
18. Thakkar, H.; Nangesh, J.; Parmar, M.; Patel, D. Formulation and characterization of lipid-based drug delivery system of raloxifene-microemulsion and self-microemulsifying drug delivery system. J. Pharm. Bioallied Sci. 2011, 3, 442-448. [CrossRef]

19. Bummer, P.M. Physical chemical considerations of lipid-based oral drug delivery-solid lipid nanoparticles. Crit. Rev. Drug Carr. Syst. 2004, 21, 1-20. [CrossRef]

20. Muller, R.H.; Runge, S.; Ravelli, V.; Mehnert, W.; Thunemann, A.F.; Souto, E.B. Oral bioavailability of cyclosporine: Solid lipid nanoparticles (SLN) versus drug nanocrystals. Int. J. Pharm. 2006, 317, 82-89. [CrossRef]

21. Plapied, L.; Duhem, N.; des Rieux, A.; Préat, V. Fate of polymeric nanocarriers for oral drug delivery. Curr. Opin. Colloid Interface Sci. 2011, 16, 228-237. [CrossRef]

22. Trevaskis, N.L.; Charman, W.N.; Porter, C.J. Lipid-based delivery systems and intestinal lymphatic drug transport: A mechanistic update. Adv. Drug Deliv. Rev. 2008, 60, 702-716. [CrossRef]

23. Sanjula, B.; Shah, F.M.; Javed, A.; Alka, A. Effect of poloxamer 188 on lymphatic uptake of carvedilol-loaded solid lipid nanoparticles for bioavailability enhancement. J. Drug Target 2009, 17, 249-256. [CrossRef] [PubMed]

24. Battani, S.; Pawar, H.; Suresh, S. Evaluation of oral bioavailability and anticancer potential of raloxifene solid lipid nanoparticles. J. Nanosci. Nanotechnol. 2014, 14, 5638-5645. [CrossRef] [PubMed]

25. Kushwaha, A.K.; Vuddanda, P.R.; Karunanidhi, P.; Singh, S.K.; Singh, S. Development and evaluation of solid lipid nanoparticles of raloxifene hydrochloride for enhanced bioavailability. Biomed. Res. Int. 2013, 2013, 584549. [CrossRef]

26. Tran, T.H.; Ramasamy, T.; Cho, H.J.; Kim, Y.I.; Poudel, B.K.; Choi, H.G.; Yong, C.S.; Kim, J.O. Formulation and optimization of raloxifene-loaded solid lipid nanoparticles to enhance oral bioavailability. J. Nanosci. Nanotechnol. 2014, 14, 4820-4831. [CrossRef] [PubMed]

27. Lu, B.; Xiong, S.B.; Yang, H.; Yin, X.D.; Chao, R.B. Solid lipid nanoparticles of mitoxantrone for local injection against breast cancer and its lymph node metastases. Eur. J. Pharm. Sci. 2006, 28, 86-95. [CrossRef]

28. Severino, P.; Andreani, T.; Macedo, A.S.; Fangueiro, J.F.; Santana, M.H.; Silva, A.M.; Souto, E.B. Current State-of-Art and New Trends on Lipid Nanoparticles (SLN and NLC) for Oral Drug Delivery. J. Drug Deliv. 2012, 2012, 750891. [CrossRef]

29. Yang, S.C.; Lu, L.F.; Cai, Y.; Zhu, J.B.; Liang, B.W.; Yang, C.Z. Body distribution in mice of intravenously injected camptothecin solid lipid nanoparticles and targeting effect on brain. J. Control. Release 1999, 59, 299-307. [CrossRef]

30. Puro, D.; Athawale, R.; Pandya, A. Design, Optimization and Characterization of Nanostructured Lipid Carriers of Raloxifene Hydrochloride for Transdermal Delivery. Nanosci. Nanotechnol. Asia 2020, 10, 57-67. [CrossRef]

31. Shah, N.V.; Seth, A.K.; Balaraman, R.; Aundhia, C.J.; Maheshwari, R.A.; Parmar, G.R. Nanostructured lipid carriers for oral bioavailability enhancement of raloxifene: Design and in vivo study. J. Adv. Res. 2016, 7, 423-434. [CrossRef]

32. Himanshu Kathuria, A.N.; Ravi, P.R. Raloxifene Loaded SLN and NLC: Comparison of In Vitro Properties and In Vivo Behavior after Oral Administration in Rats. In Proceedings of the 3rd Nano Today Conference, At Biopolis, Singapore, 8-11 December 2013; p. 186.

33. Ravi, P.R.; Aditya, N.; Vats, R. Development, validation, and pharmacokinetic application of liquid chromatographic method for estimation of raloxifene hydrochloride in rabbit plasma. Acta Chromatogr. 2012, 24, 559-573. [CrossRef]

34. Kjellman, P.; Fredriksson, S.; Kjellman, C.; Strand, S.E.; Zandt, R.I. Size-dependent lymphatic uptake of nanoscale-tailored particles as tumor mass increases. Future Sci. OA 2015, 1, FSO60. [CrossRef] [PubMed]

35. Kim, K.S.; Suzuki, K.; Cho, H.; Youn, Y.S.; Bae, Y.H. Oral Nanoparticles Exhibit Specific High-Efficiency Intestinal Uptake and Lymphatic Transport. ACS Nano 2018, 12, 8893-8900. [CrossRef] [PubMed]

36. Li, H.; Chen, M.; Su, Z.; Sun, M.; Ping, Q. Size-exclusive effect of nanostructured lipid carriers on oral drug delivery. Int. J. Pharm. 2016, 511, 524-537. [CrossRef]

37. Banerjee, A.; Qi, J.; Gogoi, R.; Wong, J.; Mitragotri, S. Role of nanoparticle size, shape and surface chemistry in oral drug delivery. J. Control Release 2016, 238, 176-185. [CrossRef] [PubMed] 
38. Muller, R.H.; Radtke, M.; Wissing, S.A. Solid lipid nanoparticles (SLN) and nanostructured lipid carriers (NLC) in cosmetic and dermatological preparations. Adv. Drug Deliv Rev. 2002, 54 (Suppl. 1), S131-S155. [CrossRef]

39. Jyotsana, N.; Sharma, A.; Chaturvedi, A.; Budida, R.; Scherr, M.; Kuchenbauer, F.; Lindner, R.; Noyan, F.; Suhs, K.W.; Stangel, M.; et al. Lipid nanoparticle-mediated siRNA delivery for safe targeting of human CML in vivo. Ann. Hematol. 2019, 98, 1905-1918. [CrossRef]

40. Uprit, S.; Kumar Sahu, R.; Roy, A.; Pare, A. Preparation and characterization of minoxidil loaded nanostructured lipid carrier gel for effective treatment of alopecia. Saudi. Pharm. J. 2013, 21, 379-385. [CrossRef]

41. Das, S.; Chaudhury, A. Recent advances in lipid nanoparticle formulations with solid matrix for oral drug delivery. AAPS PharmSciTech 2011, 12, 62-76. [CrossRef]

42. Uner, M.; Yener, G. Importance of solid lipid nanoparticles (SLN) in various administration routes and future perspectives. Int. J. Nanomed. 2007, 2, 289-300.

43. Heiati, H.; Tawashi, R.; Shivers, R.R.; Phillips, N.C. Solid lipid nanoparticles as drug carriers. I. Incorporation and retention of the lipophilic prodrug $3^{\prime}$-azido-3'-deoxythymidine palmitate. Int. J. Pharm. 1997, 146, 123-131. [CrossRef]

44. Pandita, D.; Ahuja, A.; Velpandian, T.; Lather, V.; Dutta, T.; Khar, R.K. Characterization and in vitro assessment of paclitaxel loaded lipid nanoparticles formulated using modified solvent injection technique. Pharmazie 2009, 64, 301-310. [PubMed]

45. Pezeshki, A.; Ghanbarzadeh, B.; Mohammadi, M.; Fathollahi, I.; Hamishehkar, H. Encapsulation of Vitamin A Palmitate in Nanostructured Lipid Carrier (NLC)-Effect of Surfactant Concentration on the Formulation Properties. Adv. Pharm. Bull. 2014, 4, 563-568. [CrossRef] [PubMed]

46. Kelidari, H.R.; Saeedi, M.; Akbari, J.; Morteza-Semnani, K.; Gill, P.; Valizadeh, H.; Nokhodchi, A. Formulation optimization and in vitro skin penetration of spironolactone loaded solid lipid nanoparticles. Colloids Surf B Biointerfaces 2015, 128, 473-479. [CrossRef] [PubMed]

47. Wang, J.; Chen, J.; Ye, N.; Luo, Z.; Lai, W.; Cai, X.; Lin, Y. Absorption, pharmacokinetics and disposition properties of solid lipid nanoparticles (SLNs). Curr. Drug Metab. 2012, 13, 447-456. [CrossRef]

48. Hosny, K.M.; Bahmdan, R.H.; Alhakamy, N.A.; Alfaleh, M.A.; Ahmed, O.A.; Elkomy, M.H. Physically Optimized Nano-Lipid Carriers Augment Raloxifene and Vitamin D Oral Bioavailability in Healthy Humans for Management of Osteoporosis. J. Pharm. Sci. 2020. [CrossRef]

49. Souto, E.B.; Wissing, S.A.; Barbosa, C.M.; Muller, R.H. Development of a controlled release formulation based on SLN and NLC for topical clotrimazole delivery. Int. J. Pharm. 2004, 278, 71-77. [CrossRef]

50. Muller, R.H.; Shegokar, R.; Keck, C.M. 20 years of lipid nanoparticles (SLN and NLC): Present state of development and industrial applications. Curr. Drug Discov. Technol. 2011, 8, 207-227. [CrossRef] 